\title{
Monetary Policy Rules in Practice: Evidence from New Zealand*
}

\author{
Angela Huang \\ Reserve Bank of New Zealand, New Zealand \\ Dimitri Margaritis \\ University of Waikato, New Zealand \\ David Mayes \\ Bank of Finland, Finland
}

Ten years of inflation targeting in New Zealand is used to test whether monetary policy conforms to the simple rules that have been recommended in the literature. While a Taylor rule with the standard parameters used in the US describes New Zealand monetary policy quite well, the Reserve Bank has focused more strongly on price stability, as required by its Policy Targets Agreements. Monetary policy is better described by targeting the future inflation rate as forecast by the Bank than by current inflation as in the Taylor rule. However, restricting the description of policy to the information available at the time of setting policy does not result in a much-improved explanation. There is a 'smoothing' element to the Bank's policy rather than an immediate response to every small fluctuation. There is also insufficient evidence to suggest that monetary policy has been asymmetric in treating upside inflationary pressures differently from those towards deflation (JEL E52).

Keywords: central banks, inflation-targeting, monetary policy rules.

\section{Introduction}

Central banks seek to be consistent in setting monetary policy. Consistency not merely enables them to learn in a more coherent

${ }^{*}$ We would like to acknowledge financial support from the Reserve Bank of New Zealand. Margaritis has served as an Advisor, Head of Research and Senior Research Fellow at the Reserve Bank of New Zealand. Mayes was formerly the Chief Economist and Chief Manager of the Economics Department, at the Reserve Bank of New Zealand. The usual disclaimer applies.

(Multinational Finance Journal, 2001, vol. 5, no. 3, pp. 175-200)

CMultinational Finance Society, a nonprofit corporation. All rights reserved.

DOI: $10.17578 / 5-3-2$ 
manner and not cause shocks to the economy but it helps others understand what they are trying to do. By making themselves more predictable they can reduce the costs of their actions to society, as people do not have to take out so much 'insurance' against policy surprises. Since central banks normally have price stability as their primary objective, structuring their behavior so that they can be more convincing will help anchor price expectations more firmly on the objective of policy and hence reduce its cost. A straight-forward way to achieve such predictability would be for central banks to follow some clear rule in setting policy. However, the complexity of the economy and the difficulty in disentangling signals about the likely directions in the future from the mass of data available makes such simplicity unattractive. At best such a rule would only be a guide to policy and central banks have not been keen to appear to be adopting one.

There is, however, an irony, in that ex-post analysis of central banks' behavior shows that they have indeed been taking policy actions that do not look very dissimilar from simple rules. In the best known example, Taylor (1993a) shows that the US federal funds rate can be described as a function of the current or last quarter output gap and inflation based on the output deflator. Furthermore he shows that departures from the rule help explain some of the policy 'mistakes' in the US. Hence the implication is that following the rule would not be a bad starting point for policy.

Subsequent empirical and theoretical research has shown that more complex rules may be more effective in achieving the objectives of policy (Svensson, [1997]) but Taylor-type rules remain reasonably close to the optimum. However, implementation of the rule is hindered by the lack of timely information on the output variable and its price. The data available at the time and that used in estimating ex post rules differ because of revision by the statistical authorities (Orphanides, [1997]). What central banks do and what they can do are therefore clearly different from the simple rule. In particular, central banks seek to overcome the time lags by forecasting and setting policy on the basis of what they expect to happen rather than just on estimates of the most recent events that have happened. In one respect this is just elementary common sense, as monetary policy takes some time to have its effect on inflation. The appropriate horizon for setting policy is thus the period when current actions will have their effect. Orphanides (1997) has 
shown that simple forward-looking specifications of the Taylor rule using Federal Reserve staff forecasts describe policy better than Taylor rule specifications based on real-time data. However, difficulties remain as McCallum (1993) points out in regard to the need to extrapolate trends in unobservable variables.

Taylor rules present one further difficulty in that they imply some explicit concern for output as well as inflation by the central bank. This is appropriate for the United States, where this dual responsibility exists. For other central banks such as the Bank of England, European Central Bank (ECB) and the Reserve Bank of New Zealand (RBNZ) the focus is either just on price stability or any responsibility with respect to output is explicitly secondary. In these cases the most appropriate rule might simply be inflation forecast targeting. Namely, set policy so as to maximize the chance of achieving price stability over the policy horizon. While in practice there is likely to be some element of smoothing (the $\mathrm{ECB}$, for example, explicitly targets stability over the medium term) the rule is almost a description of the objective. Output will of course remain relevant to the decision, as output gaps are an important contribution to inflationary pressure. Thus, in exploring the rules that inflation-targeting central banks appear to follow, we expect to find: (i) if they have been following a Taylor rule then the weight on output should be low or at least lower than in the US; (ii) using the information available at the time, rather than subsequently revised data, should describe actual policy more closely; (iii) forward-looking rules using forecasts will be better explanations.

Although the number of inflation targeting central banks has been growing steadily in recent years the policy has only been followed for around a decade in the longest case, New Zealand. Even that is a very short period to look at. There are other reasons for focusing on New Zealand. It has the only central bank that has published forecasts for a significant number of years and therefore permits the forward look. Furthermore, the central bank has explicitly tried to summarize its approach to policy in the form of a reaction function. This presents a unique opportunity to see if the observed behavior seems to fit with simple rules that describe the policy approach ex-ante.

Inevitably this has to be highly simplified but we do go beyond Orphanides' study to explore whether treating the policy rule as symmetric is appropriate. It is widely accepted that inflation is not a 
symmetric process (Mayes and Viren, [2000]). Moreover, the rhetoric of monetary policy in New Zealand has tended to emphasize the importance of nipping inflationary pressures in the bud. Secondly, New Zealand is a very open economy. While ignoring any extra input from outside may make sense for a much more closed economy like the United States it is appropriate to see whether the exchange rate has an additional role to play. Not only are the time lags for the influence of the exchange rate on inflation likely to be rather different from that purely from demand pressure but the exchange rate has been explicitly cited by the Reserve Bank in its descriptions of policy.

The structure of the paper is therefore as follows. Section 2 briefly reviews the nature of monetary policy in New Zealand over the period of inflation targeting and sets the analysis in the framework of previous research on monetary policy rules. Section 3 explores how well a Taylor rule describes New Zealand data, while section 4 compares it with that derived from 'real-time' data and from forward-looking specifications. In section 5 we examine whether there are signs of asymmetry in the variables in the study and in policy adjustments. We draw conclusions in section 6 .

\section{New Zealand Monetary Policy and the Framework for Analysis}

The New Zealand monetary policy regime is particular helpful to use as a test case for examining the operation of monetary policy rules because of its transparency. The objective for policy is spelt out in advance for the next five years ${ }^{1}$ in a Policy Targets Agreement (PTA) between the Governor of the Reserve Bank and the Minister of Finance (more recently Treasurer). How the Bank expects to achieve that (or its intended actions should it expect to fail) is set out in Monetary Policy Statements that have to be published at least every 6 months. ${ }^{2}$ In order

1. No PTA has actually run its full five years (Mayes, 2000). New ministers have wanted to sign new agreements.

2. In practice there have been quarterly statements of intent although until recently not all of these received the official label Monetary Policy Statement (Mayes and Razzak, 1998). 
to conduct this forward-looking explanation the Reserve Bank decided to publish its forecast.

In order to fit any single representation to monetary policy it is sensible to pick a period where policy had some coherence. There are some problems in dating this appropriately, as although the Reserve Bank Act of 1989 introduced the official framework from the date of its coming into force with signing of the first PTA on 2 March 1990, the policy had already been followed in practice (Grimes, 1996). The previous regime of targeting first money aggregates and then the exchange rate evolved and had been effectively abandoned by the end of 1988 (Wong and Grimes, 1992). We therefore start our period of analysis of the inflation-targeting regime from the beginning of 1989.

However, assuming that the period since the beginning of 1989 can be taken as a single 'regime' for statistical purposes just because it was covered by the same statute could be erroneous. It is possible to identify at least four subperiods: 1989-1991, 1992-1994, 1995-1996, and 19971998. Although the definition of price stability, as the annual rate of inflation lying between zero and 2 percent, was established at the outset, the first two PTAs were concerned with the rate at which actual inflation should be reduced to get it within that range. PTA1 (March 2 1990) required stability to be achieved by the end of 1992 , whereas PTA2 (December 19, 1990) lengthened this to the end of 1993. In practice it was achieved by the end of 1991. One might therefore want to consider reducing inflation and maintaining price stability as separate regimes.

The fourth period is separable because PTA4 (December 10, 1996) widened the target to 0 to 3 percent. However since inflation had actually been outside the target range on the upper side for nearly 2 years at that point and never below 1 percent, it is not quite clear how big a change in regime it was. As a result of the combination of improvements in forecasting and the unpleasant experience in unexpectedly exceeding the target band the Reserve Bank made a major shift in policy setting in 1995 (Mayes and Riches, [1996]). Previously, policy was to avoid going outside the target range a year ahead (Nicholl, 1995), basing the judgment largely on the direct transmission effect from foreign prices through the exchange rate onto inflation. ${ }^{3}$ Thereafter it

3. Bowden and O’Donovan (1996) interpret this as in effect setting exchange rate bands as an intermediate target. 
aimed to bring inflation into the middle of the target range 6 to 8 quarters ahead. Thus it began looking further ahead and aiming towards the middle of the road rather than trying to keep out of the gutter.

The data period we use goes up to the end of 1998. It includes a further revision in the target in PTA5 (December 17, 1997), when the Bank was able to move from targeting its own computation of 'underlying inflation' to a new CPIX, published by Statistics New Zealand, that excluded the cost of credit services from the CPI. ${ }^{4}$ However, PTA6 introduced a further change by qualifying the single focus on price stability with the words: 'In pursuing its price stability objective, the Bank ... shall seek to avoid unnecessary instability in output, interest rates and the exchange rate.' The Treasurer made it clear that this would represent a change in the Bank's behavior in setting policy. ${ }^{5}$ While the whole inflation-targeting period may not be a single regime in a detailed sense of the word, it is interesting how well it can be represented by a single Taylor rule.

\section{A. Exploring Whether Rules Describe Behavior}

Our aim in this paper is not to take a stand in the rules versus discretion debate but merely to see which if any rules seem to characterize New Zealand well and whether these conform to the stated objectives of policy. ${ }^{6}$ A policy rule can be set up among other economic indicators and

4. The New Zealand CPI was unusual in including house prices and mortgage costs. Clearly the interest rate element had to be stripped out of the inflation target otherwise the RBNZ would have been chasing its tail. Every time it tightened monetary policy measured inflation would rise, implying the need for a further tightening. In 1999 the CPI itself was altered to compute the housing element in a more commonly accepted manner and PTA6 (December 16, 1999) incorporated that into the target.

5. There have been other more detailed changes in the PTAs and the RBNZ's policy implementation (Amtenbrink, 1999). Svensson (2001), in his Review of New Zealand's monetary policy, suggests that the period between July 1997 and March 1999, when the RBNZ used a Monetary Conditions Index (MCI) as a means of communicating its monetary policy requirements, can be regarded as distinct. The March 1999 change to setting the interest rate for for overnight cash (OCR) was accompanied by a reduction in the frequency of meetings of the Monetary Policy Committee to that prevailing in the U.S. We do not report the estimates including this last period as it is rather short and may indicate some change in policy, possibly towards a Taylor rule.

6. Rules in this context can be defined as 'a reaction function, according to which policy is changed in response to the values of a few key variables' de Brouwer and O'Regan (1997, p.2). 
measures, to give policymakers another reference point in their operation of the monetary policy (Taylor, [1993a]). By viewing a policy rule as a 'policy system', i.e. a methodical, flexible approach in implementation, it can be more than a purely mechanical formula (Bryant, Hooper, and Mann, [1993], pp. 7-8). This provides a fairly accurate description of the sort of framework for monetary policy formulation in New Zealand over the last decade. With a clear numerical target, a published forecast of what is likely to happen, an explanation of how deviations from target are to be handled, a published model and view of how the economy works the New Zealand system is about as transparent a monetary policy as can be studied at present.

Following Bryant, Hooper, and Mann, (1993) we set out a monetary policy rule in terms of the deviation of a nominal interest rate, $R$, from $R^{*}$, a baseline path, as a linear function of the deviation of the target variable(s), say $X$, from its target $X^{*}: 7$

$$
R-R^{*}=\theta\left(X-X^{*}\right)
$$

The main choice for rule based regimes lies among money targeting, exchange rate targeting, nominal GDP targeting and the Taylor rule we explore (if we regard inflation forecast targeting as a special case). ${ }^{8}$ The Taylor (1993a) rule is a simple example of this framework,

$$
R=R^{*}+.5 y+.5\left(\pi-\pi^{*}\right),
$$

which places equal weights on the deviation of real output from its long-

7. This will apply even if money income is used as an intermediate target variable (Silverstone, [1978]).

8. There is of course a conceptual difference as a Taylor rule is an instrument not a target rule. Opinions are divided on the empirical merits of the various rules. What matters here is not so much which rule wins but that policy appears to be fairly robust to a range of rules that neither place a very high weight on hitting narrow inflation or output targets nor use a time horizon far different from the main time lags in the transmission mechanism (Drew and Hunt, [1999]; Amano, Coletti and Macklem, [1999]). All of these will deliver outcomes in a similar region and hence similar welfare levels. They all avoid volatility in the monetary policy instrument (some through explicit penalties on changing it). New Zealand's approach conforms clearly to the second of these criteria by design and by having a range of 2 or 3 percentage points avoids getting into the extremes under the first criterion even though there is no explicit weight assigned to output. The results from the New Zealand experience should therefore have a substantial level of applicability to other economies. 
run trend, $y$, and on the deviation of inflation $\pi$ from its target $\pi^{*}$.

We would expect any rule that applies to the RBNZ to be different, as it has been targeting just inflation and not output as well. The Bank's aim in setting policy is to get inflation on to its target (described as the middle of the target range laid down by the PTA (Mayes and Razzak, [1998]) six to eight quarters ahead. ${ }^{9}$ It has published a 'reaction function' as part of the model that is used in the forecasting and policy assessment process (Black et al. [1997]):

$$
R_{t}=\sum_{i=6}^{8} \theta_{i}\left(\pi_{t+i}^{f}-\pi^{*}\right)+R^{*}
$$

where the superscript $f$ denotes the RBNZ's forecast made in quarter $t$ for $t+i$ quarters ahead. $\theta_{i}$ is a weight set at 1.4. This is thus akin to the 'flexible inflation forecast targeting' described in Svensson (1997). 'In an uncertain world the optimal contingent rule will always dominate the optimal fixed rule' (Buiter, [1981], p. 648), because a contingent rule allows new information to be considered when the actual course of the policy instrument is set. Whereas a fixed rule only takes into account information available at the beginning of a decision-making period and cannot be altered as new information becomes available.

\section{Estimating the Taylor Rule in New Zealand}

\section{A. The Simple Rule}

If we apply a simple Taylor rule to quarterly New Zealand data, for the period 1989-98 we find that it works rather well as a description of recent policy. There is a slight problem with definitions owing to a quirk in the implementation of monetary policy in New Zealand. Unlike most countries New Zealand did not set an interest rate as such during this period. ${ }^{10}$ Instead the RBNZ said what it wanted for market conditions by specifying 90 -day bank bill rates that would be consistent with price

9. By doing that it hopes to achieve the requirements laid down in the PTA, not actually keeping inflation in the middle of the target range. The 'rule' is the means to the end.

10. From March $17^{\text {th }}, 1999$ the RBNZ has adopted a more conventional Cash Rate instead of the quantitative target. 
stability. ${ }^{11}$ Although it could achieve any given market rate by use of quantitative controls in the overnight market - it set a 'cash target' for its daily market operations - it did not normally have to use that weapon to achieve the market conditions it wanted. The combination of the threat that it could act and the statements explaining what was required were normally sufficient. The Bank thus set policy through what have often been described as 'Open Mouth Operations' (Guthrie and Wright, [2000]). ${ }^{12}$ There is thus no equivalent of the Federal Funds Rate but it seems sensible to use the rate that the RBNZ itself referred to, namely, the 90-day bank bill rate, as the best indicator of policy in the context of a Taylor rule. Given the lack of direct central bank control it will tend to have a rather higher variance than its US equivalent and will be a rather incomplete measure as it ignores the role of the exchange rate in policy setting.

To apply the Taylor rule we need to make assumptions about the 'equilibrium' real rate of interest for the period and the inflation target and decide how the output gap is to be measured. We use a simple calibration but contrast this with more flexible specifications. We assume the equilibrium real rate to be 5 percent, which is close to the average rate that prevailed over the sample period. This is higher than benchmark international rates but consistent with the tight domestic savings market situation in New Zealand and the risk premium. Similarly we assume the inflation target to be 1.5 percent, the midpoint of the current PTA. Although the mid point of the earlier agreements was 1 percent, inflation remained persistently above the mid-point and policy was not explicitly aimed at the mid point but at keeping inside the range. The response coefficient, $\theta$, is the same as Taylor's, .5. Substituting these into equation 2 and collecting terms gives:

$$
T=4.25+1.5 \pi+.5 y,
$$

where $T$ denotes Taylor's interest rate rule, $\pi$ is the inflation rate over previous four quarters, and $y$ is the output gap. We apply three versions

11. Initially in combination with a range for the exchange rate (Nicholl, [1995]) and from late 1996 in terms of a MCI (Mayes and Viren, [2000]) that combined the two in a single measure.

12. Normally the quarterly Monetary Policy Statements were used but in between, if there were shocks or the market moved too far, the Governor or other senior bank officials would issue a brief statement saying what the Bank wanted. 
of the output gap: the first as estimated by the Reserve Bank using expost data (Figure 1); the second is to replicate the original Taylor (1993a) derivation, as deviations of GDP from a log-linear trend (Figure 2); and the third a real time estimate using the Reserve Bank's methodology to estimate trend output (Figure 3). ${ }^{13}$

The summary statistics of the series used are shown in Table 1. All the data are quarterly covering the period 1989:1 to 1998:4. $R$ is the 90day bank bill rate, GAP is the real output gap, and INFLX is inflation based on the Consumer Price Index excluding interest costs (CPIX). ${ }^{14}$ It is clear that the output gap derived by applying a loglinear trend to GDP is more volatile than the ex post output gap measure provided by the RBNZ or the real-time output gap.

Figures 1-3 show that the fit of all versions of the rule is quite reasonable. We also explore an alternative (T1) rule in these graphs by setting the inflation target at the mid point of the official target ranges: 4.5-6.5 percent (1989), 3-5 percent (1990), 2.5-4.5 percent (1991), 1.53.5 percent (1992), 0-2 percent (1993-1996), 0-3 percent (1997-1998); and using a real rate of interest of 6 percent for 1989.

13. Since the Reserve Bank has only published output gap and potential output estimates relatively recently we cannot readily infer what methods estimates might have applied during the period. Up until the late 1980s the RBNZ used a sequence of large econometric models in their forecasting and simulation (Mayes and Razzak, 1998) but these broke down in the period of substantial structural change after 1984. The FPS published in 1997 was the first full-scale replacement. Conway and Hunt (1997) utilize a semi-structural approach that incorporates past inflation, an indicator of labour market conditions and a survey measure of the economy's capacity utilization rate into a multivariate filter.

14. CPIX is the definition of the target as at the end of the period. It differs slightly from the RBNZ's definition of the target, as 'underlying inflation', that was applied during most of the period, by inclusion of a small range of 'supply shocks'. The difference between the two series, mainly reflecting oil prices, is quite small (Roger, 1998). The technical criteria for excluding supply shocks to estimate underlying inflation are quite complex and defined in RBNZ (1997). Only identifiable shocks from external prices and administered prices including changes in GST were included with a minimum cut-off that the effect had to be at least a quarter of a percentage point on the index. This imparts a small downward shift to the RBNZ series over the period as the balance of shocks was inflationary. We prefer to use the series published by Statistics New Zealand both because of its current relevance and because of its objectivity. In any case it is not clear that the RBNZ series was used by price setters. The unmodified CPI probably had the greatest influence on expectations. Failure to exclude interest rates, however, has a major effect on the target and would have resulted in policy feeding on itself as we described above. This minimum adjustment was therefore essential. 
The errors and differences between the three specifications are shown in table 2. Although the mean of the difference between the actual 90-day bank bill $(R)$ and the rule $(T)$ based on real time data is the highest at 66 basis points, the standard deviation is the lowest at 150 points. The difference between the ex post (Texpost) and the real-time rule (Trealtime) is relatively small compared to the difference between the ex post rule (Tlexpost, based on loglinear trend for GDP in determining the output gap) and the real-time rule. Note, however, that the standard deviation of the quarterly change in the 90-day interest rate is 96 basis points which suggests that a random walk forecast of the interest rate is more accurate than a forecast derived from the policy rule.

If we compare actual policy with the rule, it appears from figures 1-3 that monetary policy was tight for the period mid 1990 to mid 1993, and around mid 1995 to the end of 1998. In between these periods, the rule implies that monetary policy was looser than necessary. The looseness in the initial (1989:3-1990:2) period can (in part) be attributed to the underestimate of the target in our assumptions rather than the looseness of actual policy. This becomes obvious from an inspection of the alternative rule paths (Texpost 1 or Trealtime1) in figures 1 and 3 . The tightness of the policy in the 1990-1993 period is consistent with the Bank's aim to achieve credibility at the early stages of the new monetary policy framework and bring about a prompt fall in the public's sluggish inflationary expectations formation process.

The tighter policy than prescribed by the rule since 1995 was to some extent an overreaction to the looseness of policy and ensuing inflationary pressures of the 1994-1995 period. Disinflation is not a simple linear process but rather a process that goes through a phase of initially undershooting the target (as in 1991-1992) that is likely to be followed by overshooting (as in 1994-1995). Indeed, the undershooting produces a real exchange depreciation that provides the stimulus to an economy that has been cooled off considerably as a result of monetary tightness during disinflation. Similarly, an overshooting of the inflation target gives rise to a real appreciation that can help reduce overheating pressures. More recently, policy has clearly been rather tighter than required by the rule. In particular, the tightening during the first part of 1996 and again after the Asian crises broke in mid-1997 are not called for. On the rule 

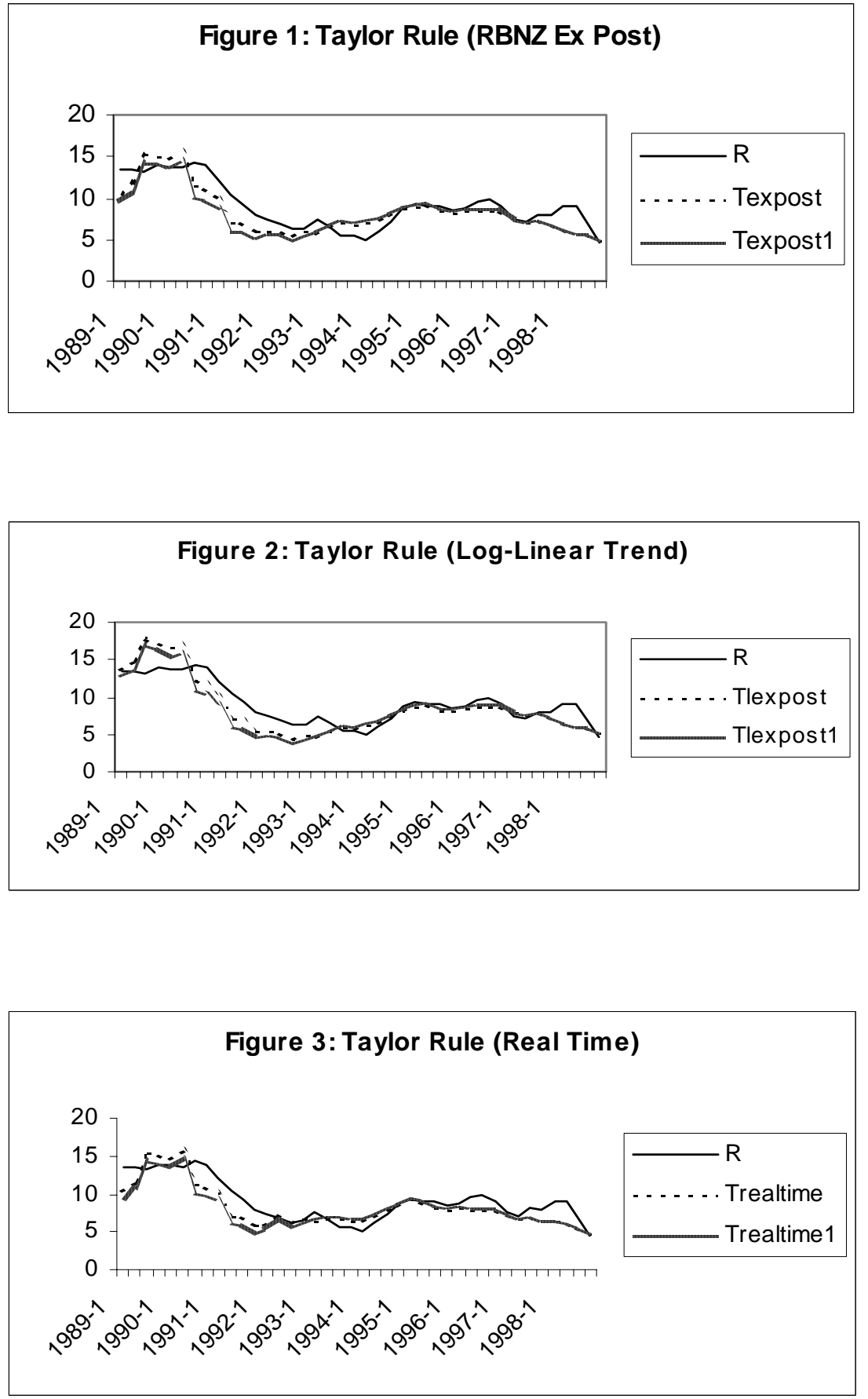
TABLE 1. Summary Statistics, 1989-1998

\begin{tabular}{lrrrrr}
\hline & MEAN & SD & MA & MIN & MAX \\
\hline$R$ & $9.05 \%$ & 2.80 & $9.05 \%$ & $4.58 \%$ & $14.28 \%$ \\
$R-R(-1)$ & $-.23 \%$ & .96 & $.77 \%$ & $-2.30 \%$ & $1.45 \%$ \\
GAP ex post (RBNZ) & $-.34 \%$ & 1.81 & $1.59 \%$ & $-3.82 \%$ & $2.22 \%$ \\
GAP ex post loglinear trend & $.01 \%$ & 2.95 & $2.43 \%$ & $-5.94 \%$ & $6.28 \%$ \\
GAP real-time & $-.49 \%$ & 1.38 & $1.11 \%$ & $-3.10 \%$ & $2.40 \%$ \\
INFLX & $2.91 \%$ & 1.87 & $2.91 \%$ & $1.10 \%$ & $7.92 \%$ \\
\hline
\end{tabular}

Note: The statistics shown for each variable are: MEAN, the mean; SD, the standard deviation; MA, the mean of the absolute value; and MIN and MAX are the minimum and

TABLE 2. Descriptive statistics of Taylor's Rule in New Zealand, 1989-1998

\begin{tabular}{lrrrrr}
\hline & MEAN & SD & MA & MIN & MAX \\
\hline$R-$ Texpost & $.61 \%$ & 1.55 & $1.33 \%$ & $-2.26 \%$ & $3.42 \%$ \\
$R-$ Tlexpost & $.44 \%$ & 1.82 & $1.43 \%$ & $-4.61 \%$ & $3.38 \%$ \\
$R-$ Trealtime & $.66 \%$ & 1.50 & $1.32 \%$ & $-2.20 \%$ & $3.24 \%$ \\
Texpost - Trealtime & $.05 \%$ & .43 & $.34 \%$ & $-1.08 \%$ & $.68 \%$ \\
Tlexpost - Trealtime & $.23 \%$ & 1.28 & $.98 \%$ & $-2.04 \%$ & $3.46 \%$ \\
\hline
\end{tabular}

Note: $R$ is the 90-day bank bill rate; Texpost = Taylor's rule using the RBNZ output gap data ex post; Tlexpost $=$ Taylor's rule using a log-linear trend measure of potential output ex post; Trealtime $=$ Taylor's rule using a real time measure of the output gap.

policy would have eased earlier and further in 1998. To the extent that policy needs are adequately described by a Taylor rule, the consistent pattern of the deviations of the actual interest rate from any version of the rule shown in Figures 1-3 seems to suggest that policy discrepancies cannot be attributed simply to specific informational problems.

\section{B. Estimated Reaction Functions}

We have thus far applied a Taylor rule with conventional parameters. A rather more instructive exercise would be to estimate the parameters, $a_{i}$ using the same functional form:

$$
R_{t}=\alpha_{0}+\alpha_{\pi}\left(\pi_{t}-\pi^{*}\right)+\alpha_{y} y_{t}+\varepsilon_{t},
$$


where $a_{0}$ is a constant, $a_{p}$ and $a_{y}$ are the response parameters for inflation and output gap, respectively, and $\varepsilon_{t}$ is a disturbance term. Following Orphanides (1997) we extend the analysis to include a partial adjustment process to account for any possible interest smoothing policy

$$
R_{t}=\rho R_{t-1}+(1-\rho)\left(\alpha_{0}+\alpha_{\pi} \pi_{t}+\alpha_{y} y_{t}\right)+\varepsilon_{t},
$$

where $\rho$ is the partial adjustment coefficient. It is argued (Brainard, [1967]; Tarkka and Mayes, [1999]) that an appropriate response to 'model' or multiplicative uncertainty is for the central bank to be rather cautious. This will result in a lagged adjustment. It is sometimes suggested that central banks actually indulge deliberately in interest rate smoothing (Rudebusch, [2001]) so as to increase the stability of the economy. There is no prima facie evidence that the RBNZ has done either of these from its Monetary Policy Statements, although the December 1996 Statement makes it clear that the Bank did not intend to respond to the very small upward and downward changes to the MCI suggested by its forecast over the coming 6 months. It preferred a more robust approach to policy.

We begin by considering the ex-post data, i.e. the most recent estimates available to us including all revisions that have been made. In practice of course this only applies to the output series as neither the price data nor the interest rate series are revised. Table 3 shows the (OLS) results for the simple static and dynamic specifications of the Taylor rule in cols. (1) and (2). ${ }^{15} \mathrm{We}$ observe as expected that while the weight on inflation is similar to that suggested by Taylor (1993a) the weight on output (in the static model) is lower and not significantly different from zero. This seems to confirm the hypothesis that the RBNZ was generally targeting inflation over the period with a relatively low weight on the output gap.

If we consider the lagged adjustment model (4) (labelled DYNAMIC in the table) the picture changes. The smoothing parameter is highly significant and around .8 in value. However, the statistical significance and magnitude of the output gap coefficients suggests an important role for real output considerations in the policy reaction function. Plots of

15. Using instrumental variables (IV) to take account of simultaneity, with 4 lags of $R$, INFLX and GAP as instruments, has little impact on the estimates. 


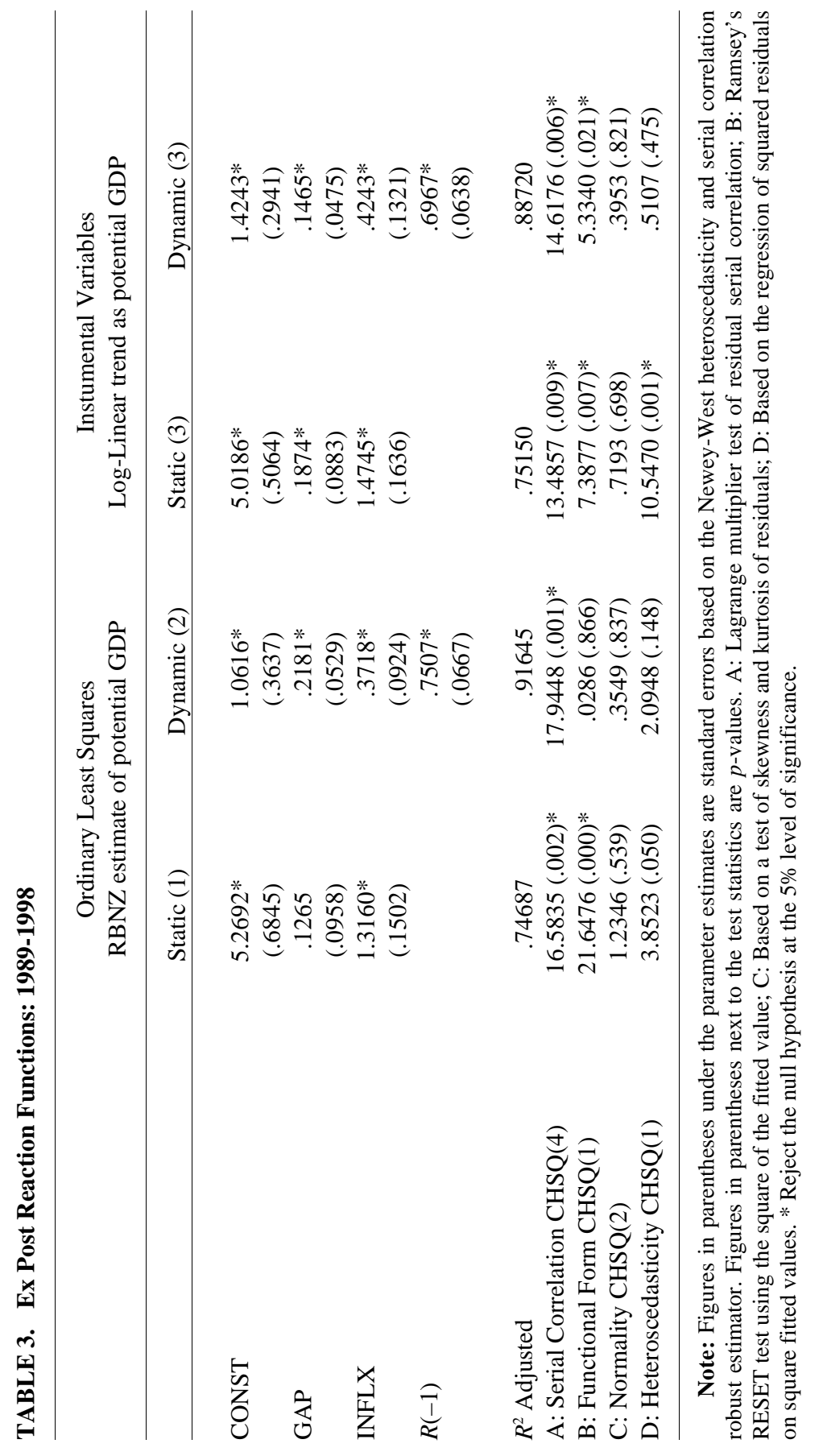


cumulative sums of recursive residuals (CUSUM) and their squares indicate that the dynamic model is more stable than the static and that there may be some problem with the static model up to 1994 that was resolved thereafter. ${ }^{16}$

The specification of the output gap does not appear to matter much for the estimation of the Taylor rule. Estimates utilizing a log-linear trend measure of potential output, columns (3) and (4) of table 3, are generally similar to those derived from the (ex post) RBNZ estimate of potential output. The main difference is that the gap coefficient is significant in both models. Indeed, the long-run values for the output gap and inflation coefficients are fairly close to the respective weights specified in Taylor's rule. The CUSUM charts indicated that the static model with the loglinear output gap is less stable than the model with the ex post RBNZ gap estimate, while the plots for the dynamic version of the model remain within the critical bounds at the 5 percent level.

\section{Real-time and Forward-looking Policy}

\section{A. Real-Time Policy Rules}

For real-time reaction functions, we require estimates of the output gap available at the time of decision-making. Since the RBNZ did not publish a set of consistent output gap estimates over the period, we have generated our own estimates by using the Bank's filtering approach. This gives an estimate of trend output that is subtracted from the real output data available at the time of setting policy. The resulting estimates shown in the second column of table 4 appear to be quite similar to those reported previously for the rule based on RBNZ ex post estimates of the output gap. The estimated weight on the inflation variable is quite robust between the static and dynamic specifications and very close to the value hypothesized in Taylor's rule. The weight on the output gap is insignificant in the static model but relatively high (and significant) in the dynamic model. There is no evidence of model instability except a twoquarter blip in 1994 in the static version of the model indicated by the CUSUM test.

16. We tested for structural breaks in the relationship but none were detected. 


\section{B. Forward-Looking Policy Rules}

While policy may have been thought forward-looking it is a separate question whether it is better represented by a forward-looking Taylor rule. Here we require forecasts of both inflation and the output gap made at the time to be included in a policy reaction function of the form:

$$
R_{t}=\rho R_{t-1}+(1-\rho)\left(\alpha_{0}+\alpha_{\pi} \pi_{t+i \backslash t}+\alpha_{y} y_{t+i \backslash t}\right)+\varepsilon_{t},
$$

where $i$ indexes the forward-looking horizon.

The RBNZ database contains quarterly forecasts of real GDP that only go back as far as March 1993. Forecast CPIX figures are also unavailable prior to September 1994, hence underlying inflation figures are used instead. We use one- to four-quarter ahead RBNZ inflation forecasts and real time output gap forecasts constructed by the authors using data from the RBNZ projections to estimate the forward looking versions of Taylor's rule for 1990:1 to 1998:4. Estimation results are presented in table 4. A backward-looking reaction function is also estimated by regressing the 90-day bank bill on last quarter's real-time output gap data and inflation rate based on the CPIX. ${ }^{17}$

The results indicate generally similar patterns for the policy response coefficients. The relative inflation weight of the policy reaction functions rises as the forecast horizon increases from period $t-1$ to period $t+1$, a similar pattern to that reported by Orphanides (1997) for the US. Over longer forecast horizons the relative inflation to output gap weights generally follow a declining pattern although their values are higher than the relative weight specified by the Taylor rule. The quality of explanation varies little over the range 1 to 4 quarters ahead and is consistent with the policy intentions described for the period up to 1995. Non-nested hypothesis testing procedures indicate that the best description of policy is achieved empirically via a model that uses oneand four-quarter ahead inflation forecasts and the current value of the output gap. Significant coefficients were not achieved for horizons

17. Note that the results of the last column are for the model that gave the best empirical description of policy. This is a model with a current period output gap and oneand four-quarters ahead inflation forecasts. The INFLX coefficient estimate in this column is the sum of the one- and four-quarter forecast coefficient estimates of 1.4514 and 1.1606, respectively, for the static model, and .70934 and .64332 , respectively, for the dynamic model. Models with forecasts in excess of four quarters were much less satisfactory. 


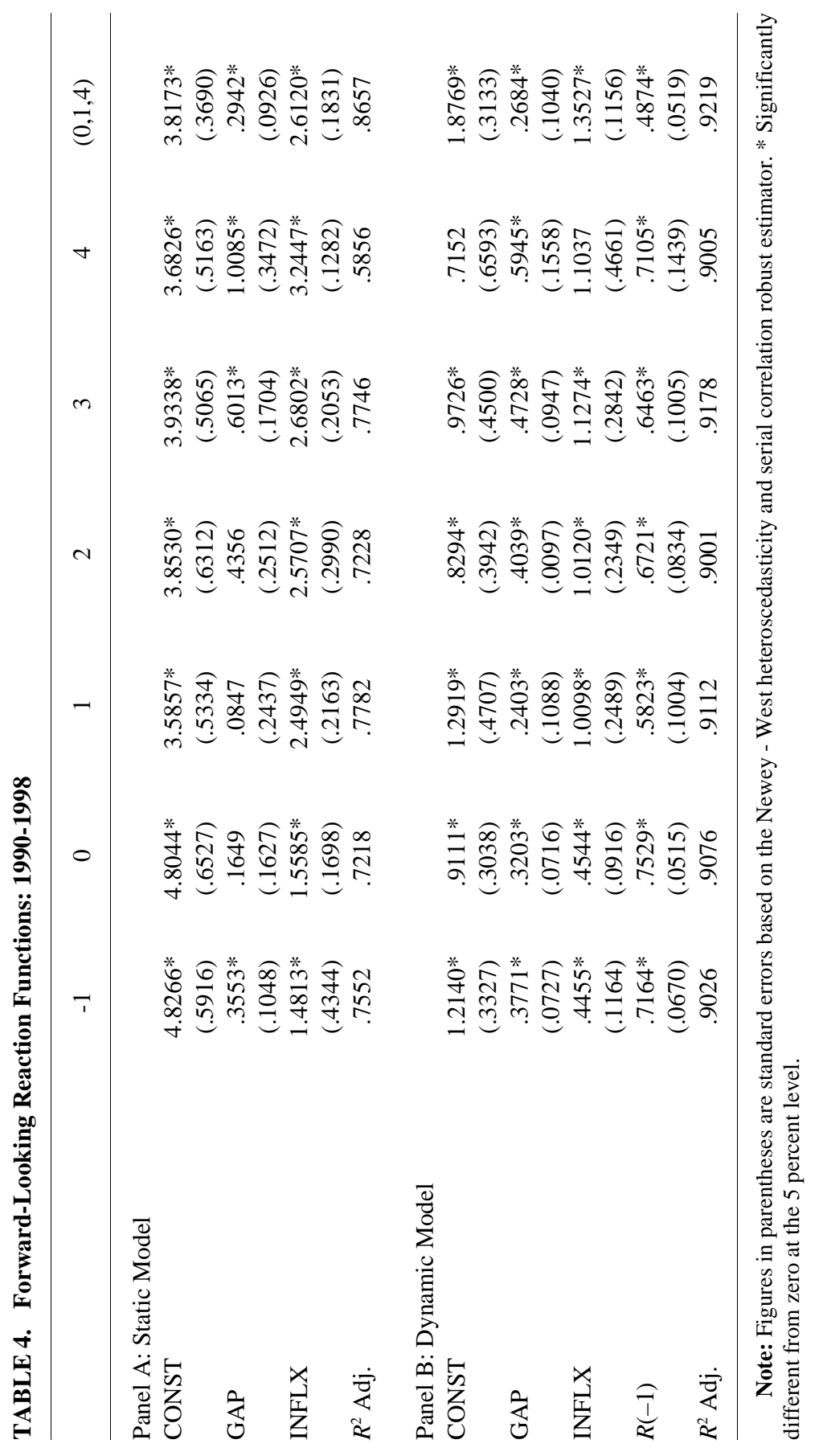


beyond 6 quarters despite the explicit 6-8 quarter ahead reaction function built into the RBNZ model, see policy reaction function (3). This may reflect changing behavior. Orphanides (1997) observes that the partial adjustment coefficient estimates under this specification consistently increase as the horizon increases. This is an indication that the lag of the interest rate serves more and more as "a proxy for the imperfectly specified output and inflation variables" (p. 20). Our results suggest that the adjustment coefficient follows a more U-shaped pattern.

\section{Asymmetric Monetary Policy}

One of the facets of monetary policy discussed within the RBNZ (Mayes and Razzak, [1998]) was whether the behavior of the economy was symmetric. If the economy itself is asymmetric then policy should also have an offsetting asymmetry (Clark, Laxton, and Rose, [1997]). Indeed Laxton, Rose, and Tambakis (1997) argue that as long as the hypothesis of asymmetry cannot be convincingly rejected policy should assume asymmetry because the costs of wrongly assuming symmetry when the economy is asymmetric are greater than from assuming it is asymmetric when it is symmetric (Mayes and Viren, [2000]). We therefore need to test for asymmetry in the data series. If the evidence suggests asymmetric adjustment, then asymmetric cointegration and error correction methods should be employed to see how the adjustment occurs. ${ }^{18}$ FPS assumes nonlinearity in the Phillips curve in New Zealand and its simulation properties are clearly asymmetric (Black et al. [1997]). However, the reaction function in the model, (3), is symmetric. Whether actual policy has been symmetric is a different matter. A textual or discourse analysis of the RBNZ's Monetary Policy Statements could easily give the impression that it has been far more concerned with excess inflation than deflation. Until the very end of the data period there was no real danger of inflation falling below 1 percent a year let alone challenging the lower bound. One might attribute this to an asymmetric distribution of shocks to the economy over the period, although Cassino (1997) suggests that this has not been the case. It might even reflect the opposite worry in macroeconomic policy as a

18. Bec, Salem and Collard (2000) explore whether policy has followed a nonlinear rule in the U.S., Germany and France and conclude that in all three countries the treatment of inflation and the output gap are not symmetric in expansions and contractions. 
whole leading to strong political action to head off any suspicion of recessions.

The evidence for asymmetry seems quite strong. Harris and Silverstone (1999a) find that Okun's law for New Zealand holds in both the long and short run only if an asymmetric approach is taken. ${ }^{19} \mathrm{We}$ therefore explore whether the variables in the Taylor rule also exhibit asymmetric patterns over the cycle. Following the approach of Sichel (1993) a test of skewness is used to determine asymmetry. 'Deepness' and 'steepness' tests are conducted on each variable. 'Deepness' implies that the troughs will be deeper than the peaks are high (or viceversa). 'Steepness' implies that contractions are steeper than expansions (or vice-versa). Thus, 'deepness' relates to the amplitude of the troughs and the peaks, while 'steepness' relates to the slope.

After decomposing the interest rate, inflation and output series into trend and cycle the detrended series can be tested for asymmetry (see Speight and McMillan, [1998]). The model hyperparameters are estimated with STAMP using the Kalman filter. There are only three cycles in each of the series over 1989:1 to 1998:4. The cycles appear reasonably symmetric ${ }^{20}$ in contrast to Harris and Silverstone (1999a) who found, using seasonally adjusted real GDP series covering 1978:1 to $1999: 1$, that the real GDP cycle displays negative skewness and expansionary steepness. Razzak (1997) also finds asymmetry in the inflation-output relationship using New Zealand data.

As a final step in the analysis we explored whether there are cointegrating relationships between inflation, the output gap and the interest rate on the basis of which a policy reaction function could be statistically supported. Since New Zealand is an open economy we included the exchange rate, represented here by the TWI (Trade Weighted Index), in the reaction function. All individual series appear to be integrated of order one, $I(1)$. Using the Johansen method we found evidence on the basis of both the maximal eigenvalue and trace test statistics to support the hypothesis that there was a single cointegrating relationship among the variables. The (normalized) maximum likelihood estimates of the cointegrating vector for the standard Taylor rule are quite similar to the OLS estimates reported in table 3. However, some

19. Harris and Silverstone (1999b) show this is also the case for some other OECD countries and Mayes and Viren (2000) show this more widely.

20. The output gap is the only series that gives rise to a significant 'steepness' test statistic. 
aspects of the results are unsatisfactory when the exchange rate is added in the policy reaction function. The coefficient on GAP is negative (although insignificant) implying that such effect as there is appears perverse and the coefficient on TWI is positive but insignificant. While we do not pursue this one might very well feel that given the emphasis placed on the exchange rate by the RBNZ over the period, inserting the exchange rate in the policy rule could turn out to improve the representation of policy. Possibly a more thorough explanation of policy can be achieved by using a system of equations which explicitly distinguish between intermediate and final policy objectives but this exercise is beyond the focus of the current investigation.

The cointegration tests performed above are based on the assumption that there is symmetric adjustment in the short-run error correction model (ECM). That is, any short-run changes in the 90-day bank bill, output gap, or inflation are strictly proportional to the absolute value of the error correction term $\left(\hat{\varepsilon}_{t-1}\right)$ in the error correction model: ${ }^{21}$

$$
\Delta R_{t}=b_{1}+b_{2} \Delta G A P_{t-1}+b_{3} \Delta I N F L X_{t-1}+b_{4} \Delta R_{t-1}+b_{5} \hat{\varepsilon}_{t-1}+\eta_{t},
$$

where $\eta_{t}$ is a white noise disturbance. However, despite not finding evidence of asymmetric adjustment for the interest rate and inflation, it is still possible for the adjustment to disequilibrium in the ECM to be asymmetric. We use an asymmetric version of the cointegration test developed by Enders and Siklos (1999) called the momentum threshold autoregressive model (M-TAR). The model can be written as:

$$
\begin{gathered}
\Delta \hat{\varepsilon}_{t}=I_{t} \rho_{1} \hat{\varepsilon}_{t-1}+\left(1-I_{t}\right) \rho_{2} \hat{\varepsilon}_{t-1}+v_{t}, \\
I_{t}=\left\{\begin{array}{lll}
1 & \text { if } & \Delta \hat{\varepsilon}_{t} \geq \tau \\
0 & \text { if } & \Delta \hat{\varepsilon}_{t}<\tau
\end{array}\right.
\end{gathered}
$$

where $v_{\mathrm{t}}$ is a white noise disturbance and $I_{\mathrm{t}}$ is the Heaviside indicator

21. The estimated value of $b_{5}(=-.42)$ in (7) suggests that 42 percent of the discrepancy between the actual interest rate and its target value recommended by the policy rule in period $t-1$ is removed in period $t$. Interest rate adjustment in (7) takes place almost entirely through the error correction term aside from a lagged interest rate change as both $b_{2}$ and $b_{3}$ are statistically insignificant. This provides further support to our earlier findings of the presence of a smoothing element in interest rate policy settings. 
function based on threshold value $\tau$. The residuals from the estimated policy reaction function (4) are used to estimate (8). ${ }^{22}$ The results suggest again that the three series are cointegrated and there is some indication (the Wald $\chi^{2}$ test statistic for $\rho_{1}=\rho_{2}$ is 2.213 with a $p$ value $=.137)$ that the speed of adjustment is more rapid for negative $\left(\rho_{2}=\right.$ $-.76)$ than for positive discrepancies $\left(r_{1}=-.33\right)$ from the threshold $(\tau=$ -.83 ). This would imply policy adjusts relatively quickly to offset increases in inflation (such that $\Delta \varepsilon_{t-1}<\tau$ ) whereas decreases in inflation are allowed to persist. ${ }^{23}$

\section{Conclusion}

In some respects it is surprising how well a simple relationship like a Taylor rule with coefficients imposed from U.S. experience can describe New Zealand monetary policy. It reflects the fact that policy has been largely counter cyclical. Re-estimating the coefficients with New Zealand data shows the expected result that monetary policy has been focused mainly on the inflation target with little weight on output fluctuations, just as required by the Policy Targets Agreements laid down by the government. We also find that policy has been relatively robust to definitions of the output gap.

More surprising is the finding that a Taylor rule that relates policy to current and past values of output and inflation is not particularly inferior to one that is forward-looking and targeting expected inflation. New

22. The value of $\tau$ is generally unknown and needs to be estimated along with $\rho_{1}$ and $\rho_{2}$. Enders and Siklos (1999) suggest using Chan's (1993) grid-search method to find a consistent estimate of the threshold. The estimated residuals from (4) are sorted in ascending order and the top and bottom 15 percent are discarded. The remaining 70 percent of the arranged values act as possible thresholds, and (8) is run with each possible threshold. The $\tau$ that results in the lowest residual sum of squares is chosen to be the preferred threshold value. This is then used to test for cointegration using the $t$-Max* and $F^{*}$-tests on the statistical significance of the coefficients in (8) proposed in Enders and Siklos (1999), as well as the Wald test to test the null hypothesis of symmetric adjustment (i.e., the two coefficients in (8) are equal).

23. The estimation of an asymmetric error correction model yields results that are similar to those from the symmetric version (7). However, the speed of adjustment towards a negative disequilibrium gap exceeds the speed of adjustment towards a positive gap, with coefficients of adjustment estimated at -.54 and -.32 , respectively. 
Zealand policy has been clearly focused on the future; the current horizon extends six to eight quarters ahead. In part this can be explained by the considerable persistence in policy. Policy has adjusted relatively smoothly and slowly to shocks. Again this experience very much follows the advice from outside experience that inflation targeting policy should be 'flexible' and not rigid and should be restrained in response (Blinder, [1998]; Svensson, [1997]) - if only because we do not know very well how the economy works (Brainard, [1967]; Mayes and Razzak, [1998]). We have been able to use the central bank's own published forecasts of inflation in order to test whether its policy was forward looking. As forecasts of the output gap do not exist for much of the period we have constructed output gap forecasts using information from the RBNZ's Economic Forecasts and Monetary Policy Statements.

Orphanides (1997) also showed that using just the data available at the time ('real time' data) enabled the rule to fit the data rather more accurately in the United States. We found this made little difference. Possibly the bank could forecast current inflation and output rather better than the initial official estimates and hence did not suffer from any great information loss compared to hindsight. Since the Bank was not using published models for much of our ten-year data period we cannot test this accurately. However, it may again be possible to test this in the future. There is some evidence that 'real time' data are more volatile than their final ex-post counterparts, which would give policy makers at the time more of problem in setting policy than is the case after the event.

The Taylor rule is symmetric yet we have many reasons for believing that the economy exhibits clear asymmetry over the course of the cycle (Harris and Silverstone, [1999b]; Mayes and Viren, [2000]). The 198998 database that we use appears to be too short to indicate this clearly although we find asymmetry in the behavior of the output gap. In so far as there is asymmetry it is of the expected form with recessions being sharper than recoveries but not so prolonged. The adjustment mechanism also appears to show only limited asymmetry. There is no clear statistical evidence that the Reserve Bank has been more prepared to tolerate recessions than inflationary expansions, although the use of real time data suggests this may have been true for the period after 1995.

Finally it is clear that omitting the exchange rate from the policy 
formation process in a small open economy like New Zealand leaves out a significant part of the story. The exchange rate has featured as an important element in Monetary Policy Statements, both as an explanation of the reaction of policy and as part of the adjustment mechanism after shocks (Mayes and Vilmunen, [1999]).

Our results do not lead to clear conclusions in favor of rules or discretion. However, they do show that whatever the authorities thought at the time, their behavior conforms quite well to simple inflation targeting rules of the 'flexible' form advocated by Svensson (1997) and others. Although output variation may not have been assigned much importance in New Zealand compared to the original Taylor specification, this is unlikely to have had much effect on the overall impact of the policy as it is robust to this degree of difference (Amano, Coletti, and Macklem, [1999]). Thus while central banks may rebel against the idea of following rules (Issing, [1999]) the behavior in the New Zealand case would not have been substantially different if a rule had been followed. As New Zealand is likely to be towards the more 'methodical' end of the spectrum in setting policy over this period as a result of its transparent framework, perhaps its ex-post behavior is also more likely to appear rule-like.

\section{References}

Amano, R.; Coletti D.; and Macklem T. 1999. Monetary policy rules when economic behaviour changes. In monetary policy under uncertainty, Reserve Bank of New Zealand workshop proceedings.

Amtenbrink, F. 1999. The Democratic accountability of central banks: A comparative study of the european central bank, Oxford: Hart Publishing.

Bec, F.; Salem M.B.; and Collard F. 2000. Nonlinear monetary policy rules: Evidence from the US, French and German central banks. Mimeo.

Black, R.; Cassino, V.; Drew, A.; Hansen, E.; Hunt, B.; Rose D.; and Scott, A. 1997. The forecasting and policy system: The core model. Research paper 43, Reserve Bank of New Zealand.

Blinder, A.S. 1998. Central banking in theory and practice. Cambridge: Cambridge University Press.

Bowden, R., and O’Donovan B.1966. Financial markets: Volatility and policy. In B. Silverstone, A. Bollard and R. Lattimore (eds.) A study of economic reform: The case of New Zealand, Amsterdam: North Holland.

Brainard, W. C. 1967. Uncertainty and the effectiveness of policy. American 
Economic Review 57 (3): 411-25.

Bryant, R.C.; Hooper, P.; and Mann, C. 1993. Evaluating policy regimes: New research in empirical macroeconomics. Brookings: Washington DC.

Buiter, W.H. 1981. The superiority of contingent rules over fixed rules in models with rational expectations. Economic Journal 91 (September): 647-670.

Cassino, V. 1995. The distribution of price shocks to the New Zealand economy. Reserve Bank of New Zealand.

Chan, K. S. 1993. Consistency and limiting distribution of the least squares estimator of a threshold autoregressive model. The Annals of Statistics 21: 520-533.

Clark, P.B.; Laxton D.; and Rose D. 1996. Asymmetry in the US output-inflation nexus: Issues and evidence. IMF Staff Papers .43 (1).

Conway, P., and Hunt B. 1997. Estimating potential output: A semi-structural approach. Discussion paper G97/9, Reserve Bank of New Zealand.

de Brouwer, G., and O'Regan J. 1997. Monetary policy rules: An application to Australia. Paper presented at the Reserve Bank of New Zealand Monetary Policy Workshop, October.

Drew, A., and Hunt B. 1999. The effects of potential output uncertainty on the performance of simple policy rules. In monetary policy under uncertainty, Reserve Bank of New Zealand.

Enders, W., and Siklos P.L. 1999. Cointegration and threshold adjustment. Working paper, University of California, San Diego.

Grimes, A. 1996. Monetary Policy. In B. Silverstone, A. Bollard and R. Lattimore (eds). A study of economic reform: The case of New Zealand, Amsterdam: North Holland

Guthrie, G., and Wright J. 2000. Open mouth operations. Journal of Monetary Economics 46: 155-89.

Harris, R., and Silverstone B. 1999a. Asymmetric adjustment of unemployment and output in New Zealand: Rediscovering Okun's law. University of Waikato working paper 99/1.

Harris, R., and Silverstone B. 1999b. Asymmetric adjustment of unemployment and output: Cross-country estimates of Okun's law. University of Waikato discussion paper 99/2.

Issing, O. 1999. The eurosystem: Transparent and accountable or "Willem in Euroland" Journal of Common Market Studies 37 (3): 503-20.

Laxton, D.; David R.; and Tambakis D. 1997. The U.S. Phillips curve: The case for asymmetry. IMF (September).

Mayes, D.G. 2000. The operation of monetary policy in New Zealand. Evidence, submitted to the Independent Review of the Operation of Monetary Policy, New Zealand Treasury.

Mayes, D.G., and Razzak W. 1998. Transparency and accountability: empirical models and policy making at the reserve bank of New Zealand. Economic Modelling 15 (3): 377-94. 
Mayes, D.G., and Riches B. 1996. The effectiveness of monetary policy in New Zealand. Reserve Bank of New Zealand Bulletin 59(1): 5-20.

Mayes, D.G., and Vilmunen J. 1999. Unemployment in a small open economy: Finland and New Zealand. Bank of Finland Discussion Paper 10/99.

Mayes, D.G., and Virén M. 2000. Asymmetry and the problem of aggregation in the Euro Area. Bank of Finland Discussion Paper 11/2000.

McCallum, B.T. 1993. Discretion versus policy rules in practice: Two critical points a comment. Carnegie-Rochester Conference Series on Public Policy, 39 (December): 215-220.

Nicholl, P.1995. Paper presented to SEACEN, Kuala Lumpur.

Orphanides, A. 1997. Monetary policy rules based on real-time data. Board of Governors of the Federal Reserve System, December.

Razzak, W. 1997. The inflation-output trade-off: Is the Phillips curve symmetric? A Policy Lesson from New Zealand. Discussion paper G97/2, Reserve Bank of New Zealand.

Reserve Bank of New Zealand. 1997. The computation of underlying inflation.

Roger, S. 1998. Core inflation: Concepts, uses and measurements. Reserve Bank of New Zealand discussion paper G 98/9, July.

Rudebusch, G. 2001. Term structure evidence on interest rate smoothing and monetary policy inertia. Federal Reserve Bank of San Francisco working paper 2001-02

Sichel, D.E. 1993. Business cycle asymmetry: A deeper look. Economic Inquiry 31(2) (April): 224-36.

Silverstone, B.D.J. 1978. A review of monetary policy reaction functions with some preliminary New Zealand illustrations. New Zealand Economic Papers, 12: 49-75.

Speight, A.E.H. and McMillan D.G. 1998. Testing for asymmetries in UK macroeconomic time series. Scottish Journal of Political Economy 45(2) (May): 158-70.

Svensson, L.E.O. 1997. Inflation targeting in an open economy: Strict or flexible inflation targeting. Public lecture, Victoria University of Wellington, November.

Svensson, L.E.O. 2001. Independent review of the operation of monetary policy, Wellington: The Treasury.

Tarkka, J. and Mayes, D.G. 1999. The value of publishing official central bank forecasts. Bank of Finland discussion paper 22/99.

Taylor, J.B. 1993a. Discretion versus policy rules in practice. CarnegieRochester Conference Series on Public Policy, 39 (December): 195-214.

Taylor, J.B. 1993b. Macroeconomic policy in a world economy: From econometric design to practical operation, New York: W.W. Norton.

Wong, J., and Grimes A. 1992. The New Zealand Monetary Aggregates. In Reserve Bank of New Zealand Monetary Policy and the New Zealand Monetary Financial System, ( ${ }^{\text {rd }}$ ed.) Wellington: Reserve Bank of New Zealand. 